Max-Planck-Institut für demografische Forschung

Max Planck Institute for Demographic Research

Konrad-Zuse-Strasse 1 - D-18057 Rostock · GERMANY

Tel +49 (0) 3812081 - 0; Fax +49 (0) 3812081 - 202;

http://www.demogr.mpg.de

MPIDR WORKING PAPER WP 2005-035

NOVEMBER 2005

The Importance of

Mortality Tempo-Adjustment:

Theoretical and

Empirical Considerations

Marc Luy (email@marc-luy.de)

This working paper has been approved for release by: James W. Vaupel (jwv@ demogr.mpg.de)

Head of the Laboratory of Survival and Longevity.

(C) Copyright is held by the authors.

Working papers of the Max Planck Institute for Demographic Research receive only limited review. Views or opinions expressed in working papers are attributable to the authors and do not necessarily reflect those of the Institute. 


\title{
The Importance of Mortality Tempo-Adjustment: Theoretical and Empirical Considerations
}

\author{
Marc Luy \\ University of Rostock, Institute for Sociology and Demography \\ Rostock Center for Research on Demographic Change \\ E-Mail: email@marc-luy.de
}

\begin{abstract}
Bongaarts and Feeney's papers on tempo distortions stirred the world of demographers and divided their community into tempo supporters and tempo opponents. The number of scholars following the tempo approach in fertility continues to grow, whereas tempo-adjustment in mortality still is generally rejected. This rejection is irrational in principle, as the basic idea behind the tempo approach is independent of the kind of demographic event. Whereas tempoadjustments in the TFR mainly lead to higher estimates on the hypothetical family size under current fertility conditions, this paper shows that tempo-adjustments in life expectancy can provide a very different picture of current mortality conditions compared to conventional life expectancy. An application of the Bongaarts and Feeney method to the analysis of the mortality gap between western and eastern Germany yields remarkable results: The differences in survival conditions between the two regions still are considerably higher than generally expected, and the survival gap between the two entities began to narrow some years later than trends in conventional life expectancy suggest. Since life expectancy without adjustment for tempo effects is one of the demographic tools most frequently used to analyze mortality, the conclusion is that we may need to revise our current knowledge of mortality trends and the driving factors behind them.
\end{abstract}




\section{Introduction}

One of the main goals of quantitative demography is the derivation of period measures with a clear and distinct meaning to analyze demographic developments in time as well as current demographic conditions in different populations. Since more than a century, demographers have been assuming to know how to provide correct calculations and interpretations of period measures, such as the total fertility rate (TFR) or life expectancy at birth $\left(\mathrm{e}_{0}\right)$. Both are summary measures representing current fertility and mortality conditions respectively, standardized for the actual age composition of populations driving the number of observed events and thus the values of crude rates. In a series of papers, however, Bongaarts and Feeney (1998, 2002 , 2003) recently have claimed that summary measures such as these should not only be standardized for age but also for tempo effects that arise whenever demographic conditions are changing. Introducing this idea with corresponding formulae for tempo-adjustment, Bongaarts and Feeney stirred the world of demographers and divided their community into tempo supporters and tempo opponents. The number of scholars following the tempo approach in fertility continues to grow, whereas the tempo approach in mortality still is generally rejected. This rejection is irrational in principle, as the basic idea behind the tempo approach is independent of the kind of demographic event. Moreover, it seems that tempo effects impact current period measures for mortality to a considerably higher extent than they do with fertility measures. In the actual discussion on mortality tempo, this aspect is given no consideration: All existing papers deal solely with theoretical and technical questions, and empirical applications are missing (beside the mentioned Bongaarts and Feeney papers e.g. Vaupel, 2002, 2005; Feeney, 2003, 2005; Guillot, 2003b, 2005; Goldstein, 2005; Rodriguez, 2005; Wachter, 2005; Wilmoth, 2005). A very interesting aspect - although not explicitly mentioned - of the initial mortality tempo paper of Bongaarts and Feeney (2002) is that the variance in life expectancy between the US, Sweden, Japan, and France decreases from 3.4 years according to conventional life expectancy to only 1.7 years according to tempo-adjusted life expectancy. Applying the Bongaarts and Feeney method to mortality differences between eastern and western Germany, I will show that adjusting period life expectancy for tempo effects produces different results than the conventional tempo-unadjusted calculations. First, however, I will explain why tempo effects impact period life tables and why they should be seen as distortions; the latter has been doubted so far by several scholars. 


\section{How mortality tempo affects period life expectancy}

In principle, Bongaarts and Feeney's idea of tempo distortions is very simple and entirely unrelated to the complex discussion it has caused, a debate surrounding especially its application to mortality. An explanation may be that mortality tempo effects have implications that seem to be in variance with established ways of modeling and analyzing mortality. The misunderstanding and confusion as to the nature of tempo effects in period life expectancy seem to be rooted in four factors:

1. Demographers usually develop their formulae in continuous time. Tempo effects, however, originate exclusively from discrete period rates and are then transferred to all demographic measures derived from such rates. This is a confusing problem when it comes to understanding Bongaarts and Feeney's approach to tempo effects in period life expectancy, since the circumstances causing tempo effects do not exist in the continuous force of mortality and thus cannot be identified in a continuous mortality model.

2. Bongaarts and Feeney's paper on mortality tempo is based on a paper published by them earlier and entitled "On the quantum and tempo of fertility". The title causes some irritations since several scholars have tried to find a quantum effect in mortality that - by definition - does not exist. Note, however, that tempo effects are not necessarily connected to a quantum. Tempo generally affects period rates and the quantum is impacted by tempo effects only if the period rates are used to estimate the demographic quantum, such as is done with the TFR. When period rates are used to derive any other demographic measures, then these measures are affected by tempo distortions. It does not matter whether they contain a quantum component or not, as is the case in period life expectancy.

3. There seems to be a misunderstanding in that Bongaarts and Feeney are assumed to have intended to estimate period measures with a certain cohort meaning. This is, however, not exactly so. As to their basic application of their method, they instead used cohort experiences in order to estimate current changes in age-specific mortality conditions. The origin of the misunderstanding is possibly found in the title of their original paper "How long do we live?" since the term "we" does only make sense in the cohort perspective and does not exist in the logic of pure period measures. Another reason may be the similarity of Bongaarts and Feeney's tempo-adjusted life expectancy with other period measures that have clearly defined cohort components, such as 
the cross-sectional average length of life (CAL). A distinct cohort meaning or a cohort projection has not been intended by Bongaarts and Feeney, however. ${ }^{1}$

4. Finally, scholars analyzing Bongaarts and Feeney's mortality tempo papers are usually confusing two questions that are fundamentally different: "Do tempo effects distort period life expectancy?" and "Do Bongaarts and Feeney's adjustment formulae provide adequate measures for adjusting tempo effects in mortality?". Both questions are important but they need to be separated in order to do justice to Bongaarts and Feeney's tempo approach.

To avoid misunderstandings, the Bongaarts and Feeney approach to tempo distortions in period life expectancy is derived by a simple hypothetical example rather than by statistical illustration in this section. The idea of mortality tempo effects is derived directly from the idea of fertility tempo effects; the latter have been known since more than half a century and are widely accepted. In this connection, Bongaarts and Feeney (1998) proposed a new method for estimating tempo bias in period fertility rates and they provided a formula to adjust the TFR for these distortions. Despite some criticism, this formula made its way successfully into demographic research, as can be seen in the rising number of papers applying the formula or confirming its effectiveness (see e.g., Lesthaeghe and Willems, 1999; Kohler and Philipov, 2001; Philipov and Kohler, 2001; Zeng Yi and Land, 2001, 2002; Sobotka 2004). As mentioned, Bongaarts and Feeney's successive work on mortality tempo effects is far from being broadly accepted. The most frequent criticism of their approach to adjust life expectancy is based on the argument that life expectancy itself is a pure tempo measure and thus cannot be adjusted for tempo effects (Guillot, 2003b; Rodríguez, 2005; Wilmoth, 2005). Both, however, are not what Bongaarts and Feeney have claimed, they instead have focused on tempo distortions in age-specific death rates, i.e. the base of life table calculation, rather than on the measures that are derived from them.

In order to demonstrate the idea of tempo effects in mortality, I use a simple illustration provided by Feeney (2003) in his unpublished paper with the apt title "Mortality tempo: a guide for the sceptic". Consider a population in which all births occur intermittently at intervals of 0.2 years and in which all deaths occurring during some base year occur at exactly the midpoint of a single year of age. Suppose that, at the end of the base year, age at death within a certain age group begins to increase linearly at the rate of 0.2 years per year for all persons, and cedes increasing at the end of the year. The Lexis diagram in Figure 1 shows this scenario 
Fig. 1: Mortality tempo effect illustrated in the Lexis diagram

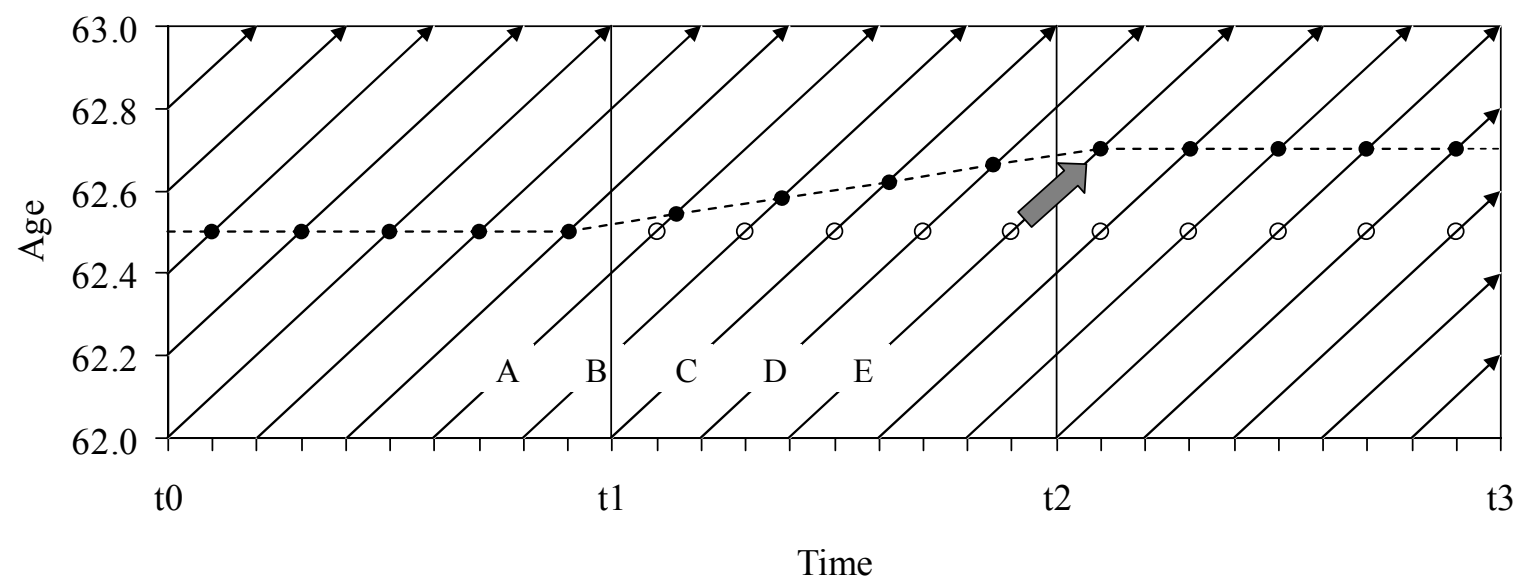

for age 62. Here, the life lines of each cohort are represented by an arrow moving through time and age. In base year t0, all deaths at age 62 occur exactly at age 62.5. During year $t 1$, age at death increases linearly with the given annual rate, from 62.5 to 62.7. This level is reached in year $\mathrm{t} 2$ and remains constant from then on. Assume further that the annual numbers of births to the population have been constant and that the proportion of deaths in any birth cohort that occurs at the $\mathrm{i}$-th age at death is constant over all cohorts (meaning unchanged mortality conditions until base year t0). The two assumptions imply that each dot in Figure 1 represents the same number of deaths and that each arrow represents the same number of persons surviving until age 62.5 .

It is important here what happens with the number of deaths in year $\mathrm{t} 1$, the year of changing mortality. The five cohorts in 11 reaching age 62.5, the exact age at which those who do not survive the given age group die according to the old conditions, are marked with the letters A to $\mathrm{E}$. Thus, cohort $\mathrm{A}$ is the oldest cohort reaching age 62.5 in year $\mathrm{t} 1$ and cohort $\mathrm{E}$ is the youngest. Due to assumed changes in mortality conditions during year $\mathrm{t} 1$, age at death of cohorts $\mathrm{A}$ to $\mathrm{E}$ increases steadily and cohort $\mathrm{E}$ is the first to reach the new age at death level of 62.7 years. Since each of these five cohorts lives longer than the preceding one, the intervals between the deaths are longer than that between the births (both intervals are identical before the year of changing mortality conditions 1 ). Consequently, the deaths to the five cohorts that reach age 62.5 during year $t 1$ are spread over a period exceeding one year. As a result, the deaths of persons belonging to cohort $\mathrm{E}$ are shifted to year $\mathrm{t} 2$, shown by the thick grey arrow in Figure 1. Following Vaupel (2005), this shift of a certain number of deaths to year $\mathrm{t} 2$ can also be interpreted in the sense of "saved lives" in year $\mathrm{t} 1$. The number of deaths in year $\mathrm{t} 1$ 
declines by 20 percent when compared to the scenario before the mortality conditions changed. This is demonstrated in Figure 1: Here, only four black dots are seen in year t1. Had mortality not changed during that year, there would have been five dots in year $t 1$, as demonstrated by the unfilled dots representing age at death to cohorts according to the old mortality conditions until year t0. Figure 1 shows that this decline in the annual number of deaths is transitory in that it disappears when the age at death stops rising. From year 2 on, the intervals between births and deaths are, again, identical and there are five dots in each subsequent calendar year.

It is clear that the decrease in the number of deaths in year t1 leads to a decline in the agespecific death rate. A decisive argument in support of the need for adjustments for tempo effects is that the period death rate for year $\mathrm{t} 1$ will be lower than that for year $\mathrm{t} 2$, although the age at death is higher in $\mathrm{t} 2$ than it is in $\mathrm{t} 1$. Let $N_{x}$ denote the number of persons reaching exact age $x$ during each of the three years shown in Figure 1 (here $x=62$ ), and let $D_{x}$ denote the annual number of deaths during years t0 and t2 (the years with five "dots" of deaths). As described above, the number of deaths in year t1 is 20 percent less than $D_{x}$. The person-years lived at age $x$ in completed years for to to t 2 are $N_{x}-0.5 D_{x}, N_{x}-0.4 D_{x}$, and $N_{x}-0.3 D_{x}$. Consequently, the age-specific death rates for age $x=62$ for the three years are

$$
M_{x, \mathrm{t} 0}=\frac{D_{x}}{N_{x}-0.5 D_{x}}, M_{x, \mathrm{t} 1}=\frac{0.8 D_{x}}{N_{x}-0.4 D_{x}} \text {, and } M_{x, \mathrm{t} 2}=\frac{D_{x}}{N_{x}-0.3 D_{x}}
$$

The subtracted terms in the denominators represent person-years not lived by the persons who die at age $x$ in completed years. Owing to the rise in age at death, this term declines each year. The quantities for the three age-specific death rates can be expressed as

$$
M_{x, \mathrm{t} 0}=\frac{1}{1 / q_{x}-0.5}, M_{x, \mathrm{t} 1}=\frac{0.8}{1 / q_{x}-0.4}, \text { and } M_{x, \mathrm{t} 2}=\frac{1}{1 / q_{x}-0.3},
$$

where $q_{x}$ denotes the probability of dying at age $x$, thus $D_{x} / N_{x}$. In a population with a high life expectancy at birth, the $q_{x}$-values for young and middle-aged adults will be close to 0.01 or 0.001 , the value of $1 / q_{x}$ will be 100 to 1,000 , and the impact of the subtractions in the denominators will be negligible. For the hypothesized model population, this shows that agespecific death rates for all but the oldest ages and infancy will decline by approximately 20 
percent between year t 0 and year $\mathrm{t} 1$ and that they will rise by approximately 25 percent between year $\mathrm{t} 1$ and year $\mathrm{t} 2$. In Bongaarts and Feeney's approach, this temporary decline represents a tempo effect. It is caused by the fact that with increasing age at death, the number of deaths in the enumerator of the death rates declines relatively stronger than do the risk years lived in the denominator of the death rates. The logic behind this argument is limited neither to the simple assumptions of this example (constant number of births, birth intervals of 0.2 years) nor to one single age group. If we increased the number of age groups and assumed that the ages at death in these groups rise at different rates, then different numbers of deaths would be shifted and the magnitude of the tempo effect would vary from one age group to another (for more details, see Feeney, 2003).

Since conventional life expectancy at birth is based on age-specific death rates calculated from the annual number of deaths and the risk years lived, there should be no doubt that this measure is affected considerably by such tempo effects (see also Horiuchi, 2005). The most illuminating paper about the consequences of such biases on the interpretation of period data was written by Vaupel (2002) who called for a distinction between "life expectancy at current rates" and "life expectancy at current conditions". ${ }^{2}$ The origin of this difference - a decisive one - is found in the basic assumption of stable (or even stationary) conditions underlying all demographic period measures. Obviously, these assumptions have an influence on the possible interpretation of period measures, something that demographers are aware of. Much more important, however, the Bongaarts and Feeney papers show that the conventional way of calculating period measures may convey a message that is wrong whenever the assumptions of stability respective stationary are not satisfied in the year or period analyzed. As to life expectancy, one can, in fact, make generalizations: If mortality declines, then life expectancy overestimates current conditions; if mortality rises, then life expectancy underestimates current survival conditions. This bias is the more marked, the more intensive the changes are during the period observed.

All demographic period measures are hypothetical estimates to standardize for current demographic conditions. Since different populations experience changes in the mean age at death differently, equivalent to changes in the mean age at childbirth, tempo effects impact them differently, as do different age compositions of the populations. Thus, tempo effects must generally be seen and treated as a distortion of period measures, as the effects of population age composition. Bearing in mind the simple example above, where the usual death rate for 
year $\mathrm{tl}$ provides a much lower value than the actual mortality conditions should produce, the question arises as to the meaning period measures based on current rates do have in a world of continuous demographic change. This holds especially when populations with entirely different demographic developments are compared, such as the populations of West and East Germany. To assure that conventional period measures do not point into the wrong direction, it is necessary to look at tempo-adjusted measures regardless of whether fertility, mortality, or any other demographic process is analyzed.

\section{Why mortality differences between western and eastern Germany call for tempo- adjustment}

The demographic changes and developments in eastern and western Germany are generally seen to present a unique possibility to understand the interaction between societal, social, and economic conditions on the one hand, and population processes on the other. The German experience thus is used to understand the reasons behind recent mortality changes. The two German regions were characterized by a demographic composition and behavior that was almost identical until 1945, followed however by 45 years under different political and socioeconomic structures and resulting in demographic developments that were entirely different (Dinkel, 1992, 1994, 1999; Gjonca et al., 2000). With unification in 1990, East Germany adopted the western societal and economic system, causing sudden changes in all of its demographic processes. These conditions - leading some scholars to describe the eastern German population as a kind of "natural experiment" (Dinkel, 1999; Vaupel et al., 2003) - generated a large number of studies on the changes in eastern German demography. In the field of mortality research, the rapid convergence of survival conditions since 1990 following roughly two decades of continuous divergence have been of central interest. The former widening and the closing in the life expectancy gap between West and East Germany were mainly caused by the age groups $60-80$, leading to the central message that "it's never too late" to increase the length of life (Vaupel et al., 2003).

Figure 2 shows the trends in period life expectancy at birth $\mathrm{e}_{0}$, using standard life table techniques for West and East German women and men for each single calendar year from 1950 to 2000. The life table calculations are based on official population statistics, i.e. figures for the living population and deaths for each calendar year and single age groups (see the description 
Fig. 2: Trends in life expectancy at birth for West and East Germany, 1950-2000
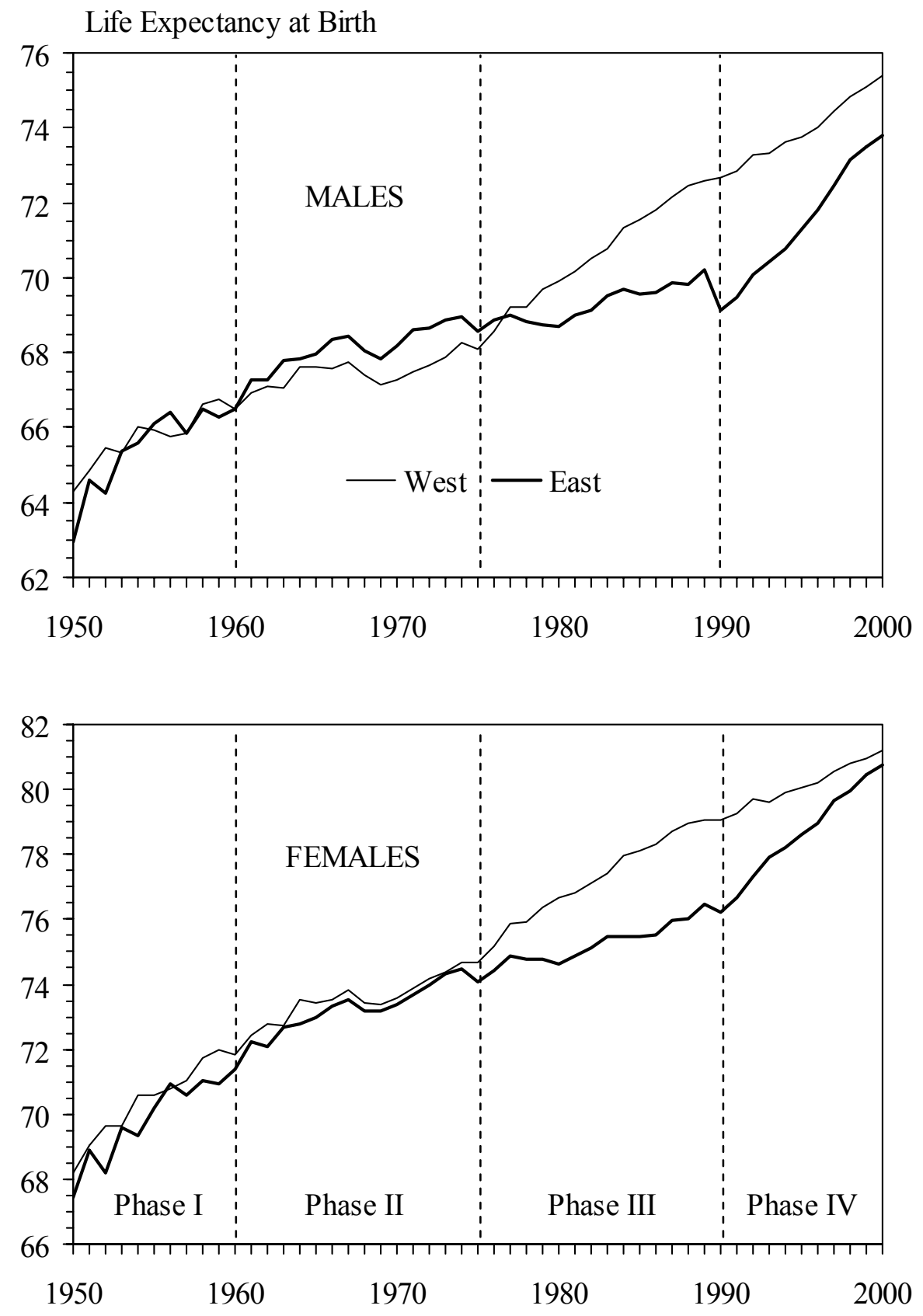

Calendar Year

in Luy 2004a). Regarding mortality differences between West and East Germany, the time span presented can be subdivided into four central phases:

- The first phase, from 1950 to roughly 1960, is characterized by irregular fluctuations, with several years of mortality crossing over. These trends correspond with the waves of influenza that swept East and West Germany during different years (Luy 2004a). No mortality differences can be detected between the two Germanys, neither for men nor for women. 
- In the second phase, roughly covering the period 1960 to 1975 , the developments in life expectancy in West and East Germany assumed more regularity, with mortality slightly higher among East German women and significantly lower among East German men. The differences in favor of East German males rose until the first half of the 1970s and reached a maximum of roughly one year in life expectancy at birth. However, the disadvantage of West German men arose mainly from different definitions of live birth in East and West Germany, thus causing lower infant mortality rates in the former GDR on purely statistical grounds. ${ }^{3}$ An analysis of age-specific differences between West and East German mortality shows that the higher life expectancy among East German men mainly (but not only) resulted from statistically lower infant mortality (Luy 2004a).

- The third phase, starting in the middle of the 1970s, is characterized by the continuous divergence for both sexes in the development of survival conditions in favor of West Germany. This development corresponds to the general divergence in mortality trends between all Western and Eastern European countries (see e.g. Caselli and Egidi, 1980; Bourgois-Pichat, 1985; Bobak and Marmot, 1996a, 1996b; Hertzman et al., 1996; Meslé and Hertrich, 1997; Vallin and Meslé, 2001; Meslé and Vallin, 2002). Figure 2 shows that the widening of the survival gap was caused by the fact that East German life expectancy at birth increased at a lower pace for both sexes, whereas life expectancy in West Germany rose more rapidly (Höhn and Pollard, 1991; Scholz, 1996; Gjonça et al., 2000; Nolte et al. 2000a). The differences peaked in 1988 for women (almost 3 years) and in 1990 for men (roughly 3.5 years).

- These peaks - virtually concurring with German unification - were followed by the continuous narrowing of the gap in West-East German mortality differences until 2000, when the difference in $\mathrm{e}_{0}$ reached about 0.5 years for women and about 1.5 years for men. As can be seen in Figure 2, as the two Germanys entered this phase the differences in life expectancy trends between them started to reverse compared to the trends in the third phase. The convergence of mortality levels now observable is due to the fact that life expectancy has been rising faster in eastern Germany than in the West since the beginning of the 1990s.

Figure 2 also shows a striking increase in mortality among East German men in 1990, a phenomenon that has been described as the East German "mortality crisis" (Dorbritz and Gärtner, 1995; Riphan, 1999; Nolte et al., 2000a, 2000b) and as characteristic of a "demographic 
shock" in connection with the changes in East Germany resulting from unification (Eberstadt, 1994). However, long-term trends in survivorship question the aptness of this description and call for an explanation of the rapid closing of the gap. An important question here is: Which factor or which factors are responsible for the trend reversal in mortality differences between West and East Germany, a trend reversal that has occured within one or two years only?

The factors discussed most are the same that are assumed to be responsible for the general mortality gap between Western and Eastern European countries (e.g. Bobak and Marmot, 1996a, 1996b; Hertzman et al., 1996), making the search for the reasons behind the mortality trends in eastern Germany a subject of major interest that exceeds the borders of Germany. It seems that finding the main cause(s) for the mortality differences between East and West Germany will be a major step forward in gaining a deeper understanding of general mortality differentials and especially of mortality differences between Western and Eastern Europe. A large and continuously increasing number of studies follow this path, based on trends in live expectancy such as shown in Figure 2 (e.g. Chruscz, 1992; Dinkel, 1994, 1999; Schott et al., 1994; Becker and Boyle, 1997; Gjonça et al., 2000; Bucher, 2002; Nolte et al., 2002; Luy, 2004a, 2004b, 2005; Mai, 2004). However, following Bongaarts and Feeney's tempo approach, we must conclude that period life expectancy based on annual death rates is an imperfect solution for reflecting period mortality conditions. This is because period life expectancy calculated in the standard way is distorted whenever it is changing.

In the previous section, it was shown that death rates are biased downward with rising mean age at death (mortality decline) and that they are biased upward when the mean age at death declines (mortality increase). Phases of mortality decline and phases of mortality increase occurred in East and West Germany at different years and with different pace, coinciding with observed trends in life expectancy differences between the two parts of Germany: During Phase 3, life expectancy increased continuously in West Germany, whereas it rose only slightly or remained constant in the East. During Phase 4, life expectancy rose more steeply in eastern Germany than in the West. If these different trends are causing tempo distortions in the sense of Bongaarts and Feeney, then all studies on the causes of East German excess mortality would be based on data leading to a distorted picture of mortality conditions in the two German regions and thus to the differences between them. 


\section{Methods for estimating tempo-adjusted life expectancy}

In order to estimate tempo-adjusted life expectancy for West and East Germany, I follow the approach of Bongaarts and Feeney (2002), who defined the tempo effect $S(t)$ in life expectancy in a year $t$ as the absolute difference between the observed life expectancy at birth $e_{0}(t)$ and the tempo-adjusted life expectancy at birth $e_{0}{ }^{*}(t)$ (which Bongaarts and Feeney called the "average age at death"), thus

$$
S(t)=e_{0}(t)-e_{0}^{*}(t)
$$

Measure $e_{0}{ }^{*}(t)$ is defined as the average age at death in a population with a constant number of births. This measure is closely related to the "cross-sectional average length of life" (CAL) introduced by Brouard (1986) and Guillot (2003a) but it is not identical (see Guillot 2003b). In a subsequent paper, Bongaarts and Feeney (2003) presented three different possibilities to estimate in a similar manner tempo-adjusted period life expectancy from complete cohort data on births, deaths, and migration in order to reconstruct empirically a constant birth population for a certain period. Detailed data such as these do not exist for the West and East German populations, however. When cohort data on births, numbers of death, and migration cannot be used (at least for a time span long enough), $e_{0}{ }^{*}(t)$ can be estimated by solving the equation

$e_{0}(t)=e_{0}^{*}(t)-\frac{1}{b} \ln \left(1-\frac{d e_{0}^{*}(t)}{d t}\right)$

for $e_{0}{ }^{*}(t)$ from conventional life table estimates, based on the assumptions that mortality under age 30 can be neglected and that the annual changes in the force of mortality follow a shifting Gompertz function. ${ }^{4}$ For the detailed derivation of this formula, see Bongaarts and Feeney (2002). As proposed by Bongaarts and Feeney (2002), value $b$ is estimated by fitting a Gompertz model to single-year age-specific death rates for ages 30-90. ${ }^{5}$ Although cohort experiences are generally connected with age-specific period death rates and thus with the estimates of the Gompertz parameter $b$, equation (2) does not contain a direct cohort component and includes only elements derived from period data.

Table 1 presents the estimates of parameter $\mu_{0}(\mathrm{t})$ and the average of parameter $b$ for the analyzed populations from 1975 to 2000 . The estimates for $b$ for the whole series of single obser- 
vation years are shown in Appendix (c) and (d) of this paper. Corresponding to the observed death rates, $\mu_{0}(\mathrm{t})$ declines over time for all four populations. Similar to what is known for several other countries, the estimated values of $b$ are close to 0.09 among males and 0.10 among females for both West and East Germany. During the observation period, the annual estimates of $b$ vary only little over time in each of these populations, as can be seen from the standard deviation of $b$ in Table 1 or from the single values in Appendix (c) and (d). As with the populations analyzed by Bongaarts and Feeney (2002), the Gompertz model fits the observed adult death rates very well, with the average variance explained $\left(\mathrm{R}^{2}\right)$ being more than 99 percent. Based on these data, I used a three-step procedure similar to the procedure proposed by Bongaarts and Feeney (2002). First, I calculated the annual estimates of $e_{0}(t)$ from 1950 to 2000 with life tables that have mortality under age 30 set to 0 . Next, I smoothed these estimates by fitting a sixth degree polynomial, using the computer program $\mathrm{R}$. The resulting values for the smoothed time series for life expectancy $e_{0}(t)^{S}$ are provided in Appendix (c) and (d). Figure 3 shows the corresponding functions together with the original estimates for $e_{0}(t)$ with no mortality under age 30 . It can be seen that the trends in $e_{30}+30$ (which corresponds to setting mortality below age 30 to 0 ) are very similar to the trends in $\mathrm{e}_{0}$, shown in Figure 2 . They differ slightly in the years 1950 to 1970 only, owing to the fact that mortality below age 30 (and especially infant mortality) had a higher impact on overall life expectancy than it has had in years more recent. Note that the significant decrease in life expectancy at birth $e_{0}(t)$ for East German men in 1990 diminishes in the smoothed values $e_{0}(t)^{S}$.

Tab. 1: Estimates of the parameters of the Gompertz mortality change model, males and females, West and East Germany, 1975-2000

\begin{tabular}{llllll}
\hline & & & \multicolumn{3}{c}{ Average 1975-2000 } \\
\cline { 4 - 6 } & $\mu_{0}(1975)$ & $\mu_{0}(2000)$ & $b$ & St. dev. $b$ & $\mathrm{R}^{2}$ \\
\hline West Germany, Males & $6.161\left(\cdot 10^{-5}\right)$ & $3.142\left(\cdot 10^{-5}\right)$ & 0.092 & 0.0020 & 0.991 \\
East Germany, Males & $4.737\left(\cdot 10^{-5}\right)$ & $3.568\left(\cdot 10^{-5}\right)$ & 0.094 & 0.0026 & 0.993 \\
West Germany, Females & $2.206\left(\cdot 10^{-5}\right)$ & $7.644\left(\cdot 10^{-6}\right)$ & 0.104 & 0.0028 & 0.993 \\
East Germany, Females & $1.591\left(\cdot 10^{-5}\right)$ & $7.483\left(\cdot 10^{-6}\right)$ & 0.108 & 0.0040 & 0.995 \\
\hline
\end{tabular}


Fig. 3: Observed life expectancy at birth $e_{0}(t)$ and smoothed estimates $e_{0}(t)^{S}$ (sixth degree polynomial), West and East Germany, 1950-2000 (no mortality under age 30)

(a) West Germany, Males

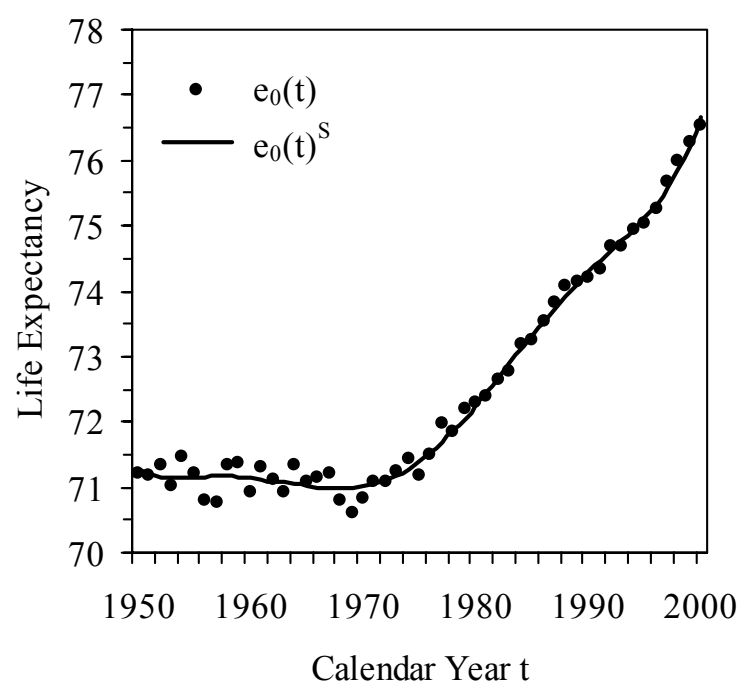

(c) West Germany, Females

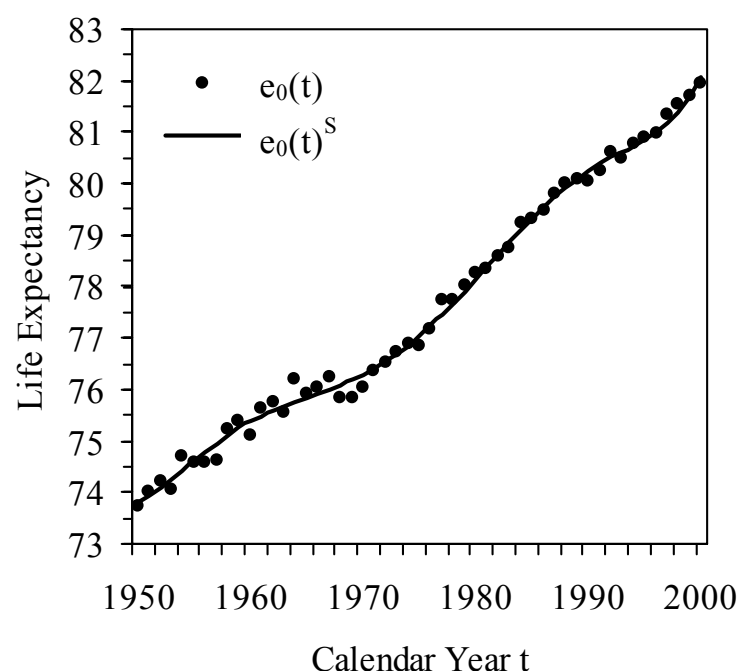

(b) East Germany, Males

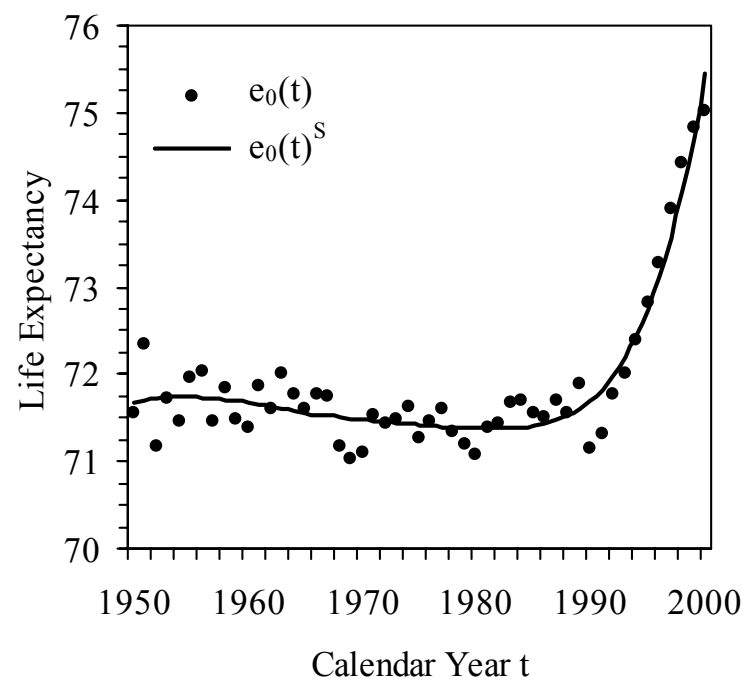

(d) East Germany, Females

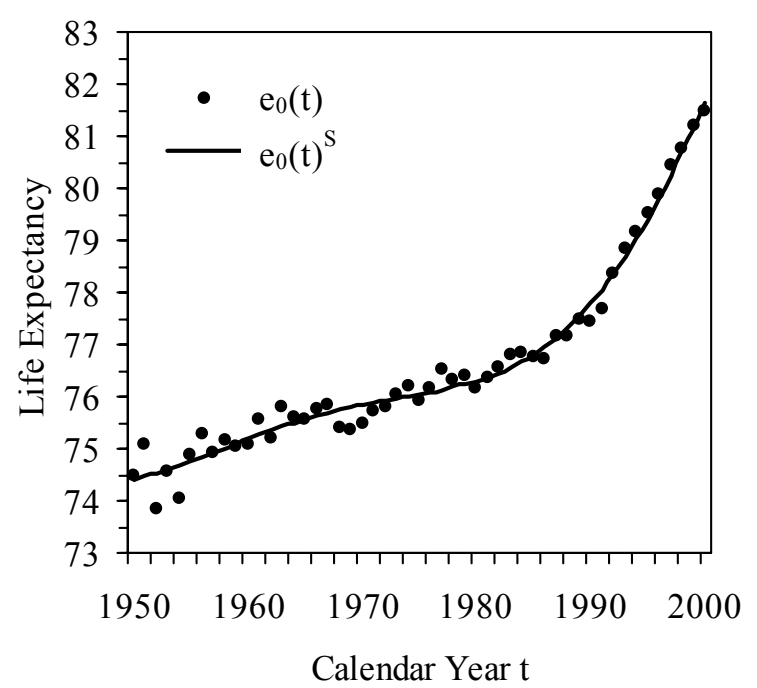

For estimating tempo-adjusted life expectancy $e_{0}{ }^{*}(t)$, the original values for $e_{0}(t)$ are substituted by values $e_{0}(t)^{S}$ derived from the polynomial functions. To finally solve equation (2) for $e_{0}{ }^{*}(t)$, I used the so-called Euler's method, described in its general form in Appendix (a) of this paper, with $S(1950)=2$ as the initial condition for the differential equation. From equation (1) then follows that $e_{0}{ }^{*}(1950)$ can be directly estimated from $e_{0}(1950)-S(1950)$. For instance, for West German males it follows that $e_{0}{ }^{*}(1950)=71.28-2.00=69.28$. This value represents the assumed tempo distortion for mortality changes until the year 1950, which was 
equally set for all populations observed, and thus the female and male populations of West and East Germany. Note that the results for the analyzed years after 1975 are insensitive to this assumed initial condition for the year 1950. An application of Euler's method leads to an estimate for the tempo-adjusted life expectancy $e_{0}{ }^{*}(1951)$ for the next year from the equation:

$e_{0}^{*}(1951)=e_{0}^{*}(1950)+\left\{1-\exp \left[-b(1950) \cdot\left(e_{0}(1950)^{S}-e_{0}^{*}(1950)\right)\right]\right\}$

or generally written from

$e_{0}^{*}(t+1)=e_{0}^{*}(t)+\left\{1-\exp \left[-b(t) \cdot\left(e_{0}(t)^{S}-e_{0}^{*}(t)\right)\right]\right\}$

Equation (3) was used for estimating a complete time series of values for tempo-adjusted life expectancy at birth (with no mortality under age 30) until 2000 for West and East German females and males. The detailed derivation of equation (3) is shown in Appendix (b).

\section{Trends in tempo-adjusted life expectancy in West and East Germany}

Figure 4 shows the trends in conventional and tempo-adjusted life expectancy at birth (no mortality under age 30 in both cases) from 1975 to 2000 for West and East German females and males. The graph for West German females (Figure 4c) is very similar to the figures for US and Japanese women presented by Bongaarts and Feeney (2002: 24). As can be seen in Figure 3(c), West German females represent the only population of the four populations analyzed with an observed life expectancy at birth increasing almost constantly since 1950. Thus, the tempo distortion $S(t)$ (defined as the difference between observed and tempo-adjusted life expectancy) is relatively constant among West German females during the observation period. Since among the other three populations improvements in life expectancy developed much later (West and East German males) or at a significantly changing pace (East German females), tempo distortions must vary considerably when compared to West German females. This is well reflected by the results gained for $e_{0}{ }^{*}(t)$ and $S(t)$, as can be seen in Figure 4. In all cases, the estimated tempo distortions agree with the logic of mortality tempo effects described in the previous chapters. 
Fig. 4: Observed life expectancy at birth $e_{0}(t)$ and estimated mean age at death $e_{0}{ }^{*}(t)(a d-$ justed life expectancy at birth) with tempo distortion $S(t)$, West and East Germany,

1975-2000 (no mortality under age 30)

(a) West Germany, Males

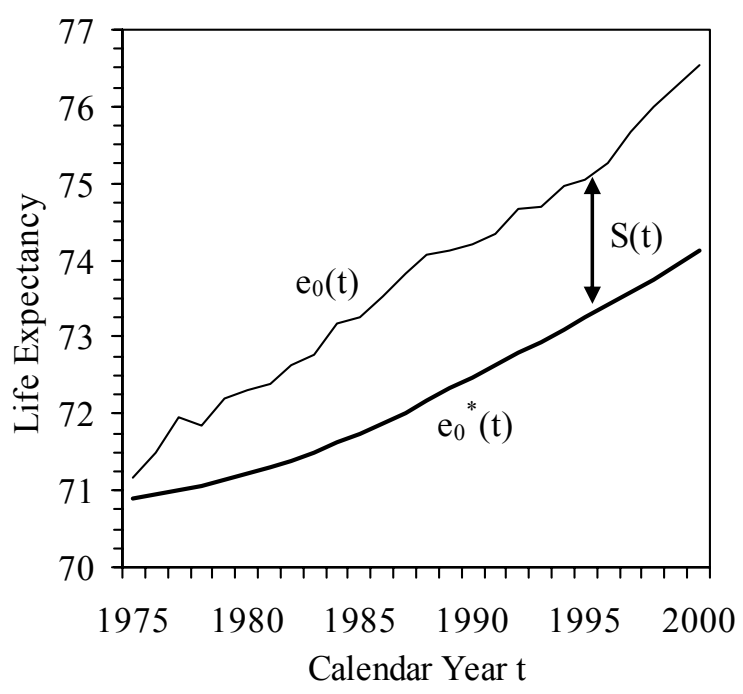

(c) West Germany, Females

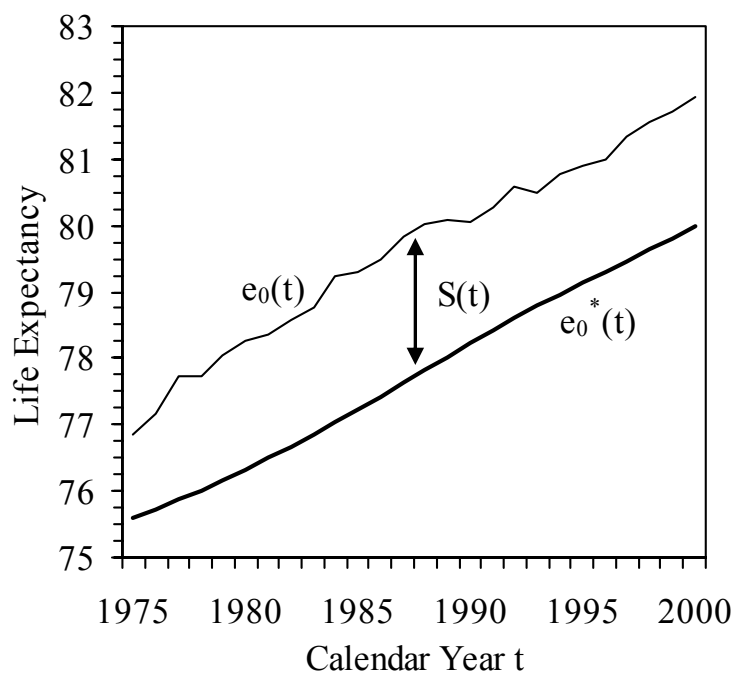

(b) East Germany, Males

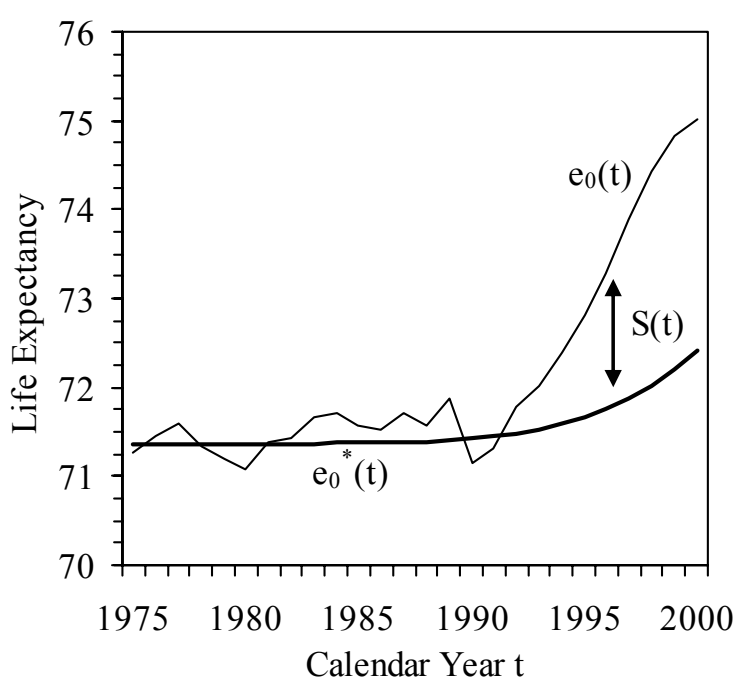

(d) East Germany, Females

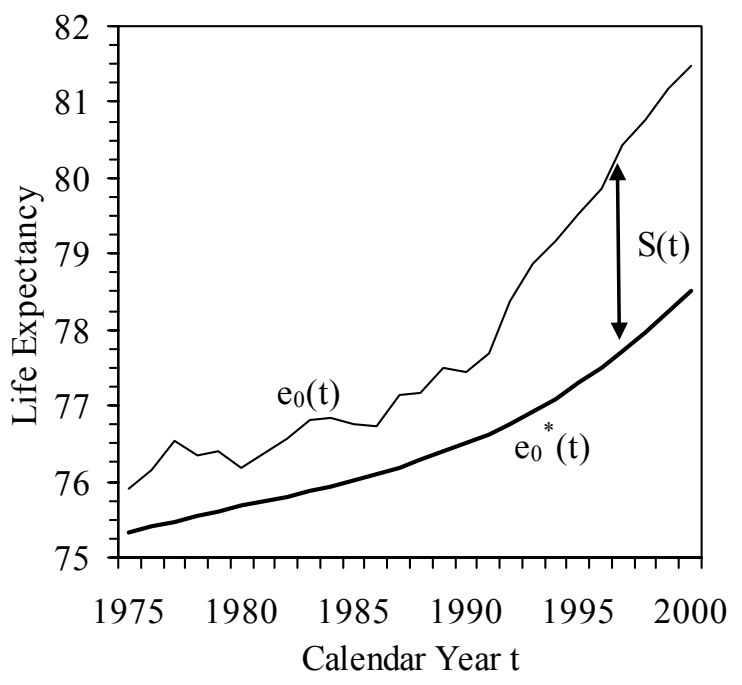

This is very clear when comparing Figures 3 and 4 . The tempo distortion $S(t)$ was very low among West German men in 1975 and then increased steadily until the second half of the 1980s when the difference between observed and tempo-adjusted life expectancy reached an almost constant level (Figure 4a). It is clear from Figure 3(a) that life expectancy among West German men remained more or less unchanged between 1950 and 1970, thus one cannot expect a noticeable tempo distortion in the mid 1970s. Rising life expectancy after 1970 is 
caused a by shift in the average age at death and thus the tempo-adjusted life expectancy also starts to increase, although at a lower pace than the observed life expectancy. That is consistent with the described cause of mortality tempo effects. According to Bongaarts and Feeney's approach delays in cohort deaths accumulate over time as mortality keeps changing (see also Guillot, 2005). Among East German males, life expectancy remained constant or even declined slightly until the end of the 1980s and then started to rise at a pace much higher than in any phase of life expectancy trends in West Germany (Figures 3a and 3b). Consequently, tempo-adjusted life expectancy $e_{0}{ }^{*}(t)$ did not differ from conventional life expectancy until the beginning of the 1990s and then began to increase at a considerably lower rate compared to $e_{0}(t)$. The annual rise in tempo-adjusted life expectancy after 1990 appears to be similar among West and East German males. Among East German females, too, the extent of tempo distortions in conventional life expectancy climbed during the observed period. From Figure 3(d) we know that their life expectancy rose in the period preceding unification, although at a lower pace than it did among their West German counterparts. As a result, tempo distortions, i.e. the difference between tempo-adjusted and unadjusted life expectancy, remained at an almost constant level between 1975 and 1990. However, the difference between $e_{0}(t)$ and $e_{0}{ }^{*}(t)$ started to increase at the end of the 1980s when conventional life expectancy rose at a higher pace - a phenomenon similar to what has been observed among eastern German males (Figures $4 \mathrm{~b}$ and $4 \mathrm{~d}$ ).

An interesting question is how differences in life expectancy between West and East Germany developed in the observation period 1975 to 2000 when adjusted for tempo distortions. The corresponding results are given in Figures 5 and 6 for males and females respectively; the single values can be found in Table 2. The thinner lines in the two graphs represent the absolute difference between West and East Germany in conventional life expectancy and the bold lines show those in tempo-adjusted life expectancy. Figure 5 depicts, again, the rapid decrease in conventional life expectancy differences after 1990 following an almost continuous increase since the beginning of the observation period. Whereas West German males enjoyed a higher life expectancy according to conventional calculation methods since 1976, East German men showed a higher tempo-adjusted life expectancy until 1981. Note that the different definitions of live birth do not affect the results presented in this section and thus there seems to be a real East German survival advantage among men in the 1970s. Only after 1981 did the differences switch to an advantage for West German males, although much less so than the results based on conventional life expectancy. The graph demonstrates that the trend of 
Fig. 5: East-West German difference in life expectancy at birth for conventional life expectancy $e_{0}(t)$ and tempo-adjusted life expectancy $e_{0}{ }^{*}(t)$, males 1975-2000 (no mortality under age 30)

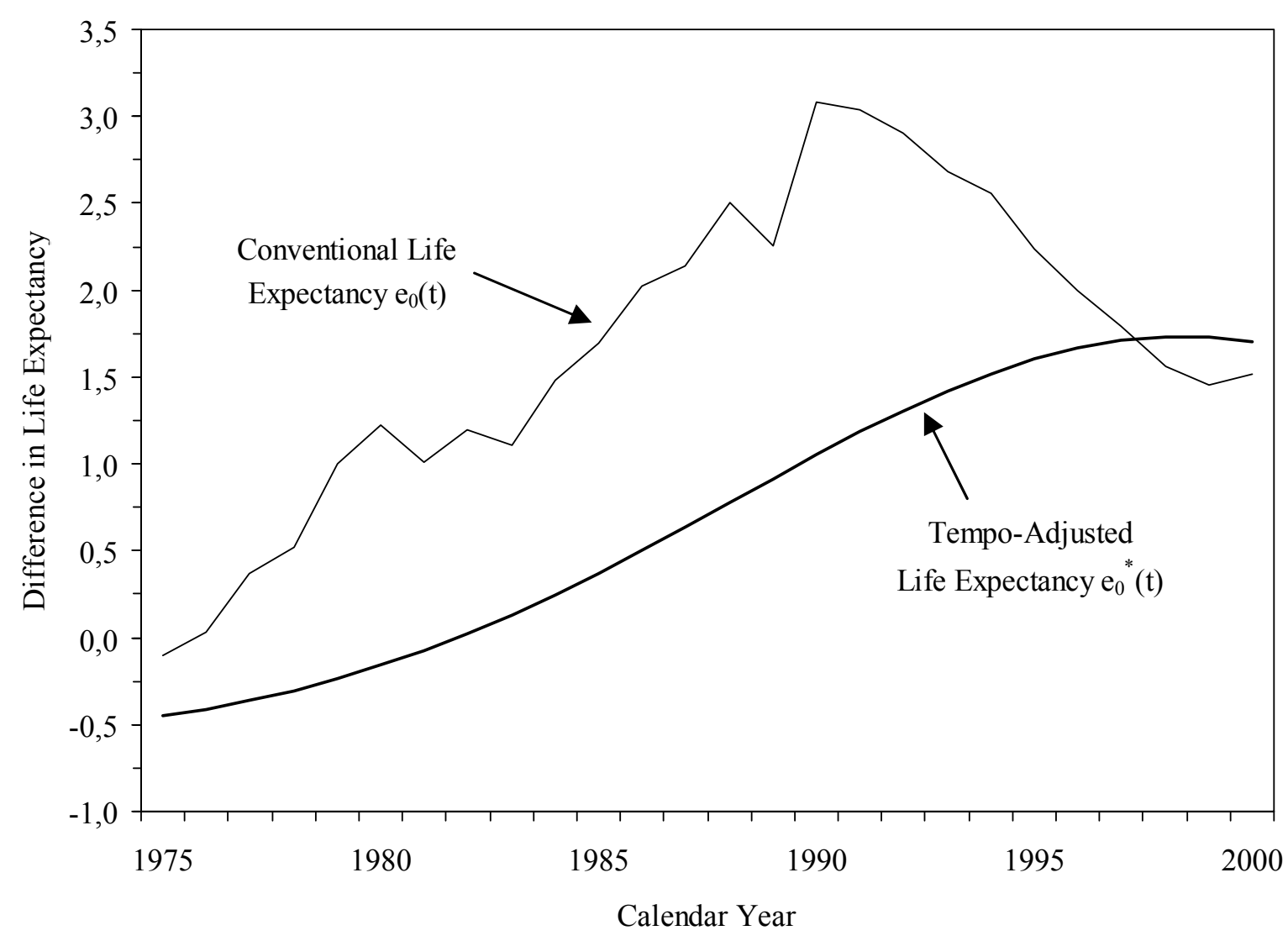

increasing West-East differences occurred at a considerably lower pace once life expectancy is adjusted for tempo effects. In 1990, when the difference in conventional life expectancy between West and East German men reached a peak of 3.08 years, the difference in tempoadjusted life expectancy was only 1.05 years, i.e. two years less. The finding that the latter differences did not decrease since unification but continued to increase until the end of the 1990s is even more interesting. While the difference in conventional life expectancy between western and eastern German males declined to roughly one and a half years in 2000, those in tempo-adjusted life expectancy is now even higher, with a difference of about 1.7 years. Only at the end of the 1990s did the trend in increasing differences in tempo-adjusted life expectancy lower its speed, pointing to convergence solely in the very last year of the observation period. 
Fig. 6: East-West German difference in life expectancy at birth for conventional life expectancy $e_{0}(t)$ and tempo-adjusted life expectancy $e_{0}{ }^{*}(t)$, females 1975-2000

(no mortality under age 30)

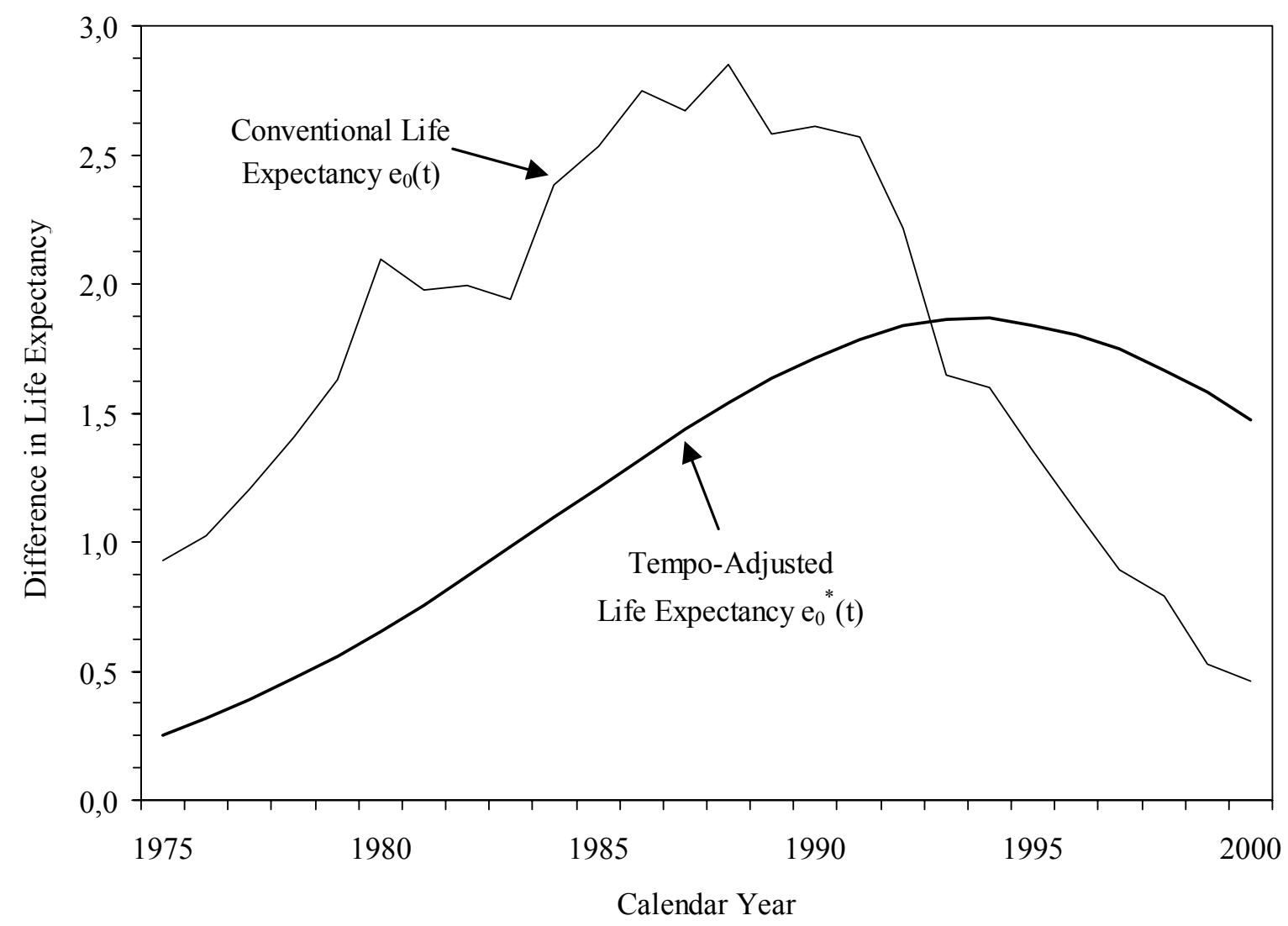

The results for the West-East German differences among females are similar to those just described for males. The survival advantage for West German females is considerably lower when tempo-adjusted life expectancy is used instead of conventional life expectancy. Since among females the trends in conventional life expectancy in the two pre-unification Germanys were not as different as that of their male counterparts, the relative trends of increasing West-East-differences in conventional and tempo-adjusted life expectancy are more similar compared to the differences between West and East German males, i.e. the tempo distortions in the measured trend are less marked. However, this does not hold for the absolute differences in $e_{0}(t)$ and $e_{0}{ }^{*}(t)$. Whereas the difference in conventional life expectancy increased to 2.85 years in 1988, those in tempo-adjusted life expectancy did never exceed 1.9 years. Similar to the situation among men, the differences in tempo-adjusted life expectancy between West and East German females did not decline with unification parallel to conventional life expectancy but rose until the mid 1990s. The trends in conventional and tempo-adjusted life expectancy crossed over between 1992 and 1993. From then on, the survival advantage of 
Tab. 2: East-West German difference in life expectancy at birth according to conventional $e_{0}(t)$ and tempo-adjusted $e_{0}{ }^{*}(t), 1975-2000$ (no mortality under age 30)

\begin{tabular}{ccccc|ccccc}
\hline \multicolumn{5}{c}{ Years before unification } & \multicolumn{5}{c}{ Years after unification } \\
\hline Year & \multicolumn{2}{c}{ Males } & \multicolumn{2}{c|}{ Females } & \multicolumn{3}{c}{ Males } \\
\hline
\end{tabular}

West German females measured with tempo-adjusted life expectancy is considerably higher when compared to the results based on tempo-unadjusted values. Although a decreasing trend in mortality differences between western and eastern German females is also evident with tempo-adjusted life expectancy since the mid 1990s, the remaining differences in favor of western German women are still considerably higher. While the disadvantage of eastern German women decreased to 0.46 years in the year 2000 according to conventional life expectancy, the tempo-adjusted difference still shows 1.5 years. 


\section{Discussion}

This paper provides both, a support of Bongaarts and Feeney's tempo approach in mortality as well as its first empirical application exceeding pure practical demonstration. If we accept the need for tempo-adjustment in the period TFR, we equally have to accept the need for it in period life expectancy. The basic idea of the TFR is to estimate the fertility quantum under current fertility conditions as a standardized indicator for current fertility conditions. Changes in the mean age at childbirth cause tempo effects which, in turn, affect age-specific fertility rates and thus the TFR that is based on them. Exactly the same holds for period life expectancy. The basic idea of life expectancy is to estimate the average length of life under current mortality conditions as a standardized indicator for current mortality conditions. Changes in the mean age at death are causing tempo effects which affect age-specific death rates and thus life expectancy that is based on them.

In principal, the Bongaarts and Feeney adjustment formulae for the TFR and for life expectancy follow the same basic idea. In the case of fertility the tempo adjustment formula is based on a shift of the age-specific fertility schedule, in the case of mortality the tempo adjustment formula is based on a shift of the age-specific mortality schedule. Since, however, the TFR and life expectancy are fundamentally different in their structural designs, the adjustment formulae must include fundamental differences. The tempo-adjusted TFR depends only on age-specific fertility rates within a small neighborhood of the analyzed calendar year. This does not hold for the Bongaarts and Feeney formula for tempo-adjusted life expectancy. The major difference to the fertility procedure is that the proposed adjustment method for life expectancy uses a series of previous period life tables. Consequently, it is clear that the Bongaarts and Feeney formula reflects past mortality conditions in a certain way. But in the logic of tempo distortions, this does not necessarily represent an inconsistency, especially when past changes in mortality conditions are steady and continuous, what approximately holds for adult ages in developed populations and in the last decades. Since these are exactly the restrictions that Bongaarts and Feeney (2002) have made to the applicability of their tempoadjustment formula for life expectancy, we should not see a problem in the fact that it leads to values close (but not exactly) to a weighted moving average of past period life expectancy, as Wachter (2005) has shown. Just the contrary, in restricting the application to the industrialized countries of the recent past, this property of the Bongaarts and Feeney formula is consistent with the theoretical idea of tempo distortions in life expectancy. 
However, we cannot see the Bongaarts and Feeney formula providing a perfect measure for tempo-adjusted period mortality conditions. This demand on the Bongaarts and Feeney method must be excluded by noting that in practice all basic assumptions behind the formula will never be fulfilled. Thus, we should see the Bongaarts and Feeney formula as an attempt to standardize for tempo effects in period life expectancy to obtain a better measure for comparing period mortality conditions. It is, however, not clear to which extent the Bongaarts and Feeney method catches real tempo effects and it is not possible to assess whether it presents a maximum distortion in the sense that the truth lies somewhere between conventional and tempo-adjusted life expectancy as discussed by Vaupel (2005). Nevertheless, it is important to separate these methodological aspects from the question of the general existence of tempo effects in period life expectancy.

The empirical results presented in the previous section are striking and may be very important for the general understanding of several phenomena connected with changing mortality: Once life expectancy is adjusted for tempo effects, the differences between western and eastern Germany do not decrease immediately after unification and ten years later still are considerably higher when compared to the differences in conventional life expectancy. This indicates that the discussion on the reasons for the trends in mortality differences between western and eastern Germany of the last years might have been based on inappropriate measures and thus have led to the wrong direction. The puzzle has been that although several scholars have conducted research on that subject, no factor was found that could explain the observed trends in conventional life expectancy at birth. However, according to the trends in East-West German differences in tempo-adjusted life expectancy, the explanatory factors do obviously not necessarily decrease the gap in life expectancy by more than two years among females and by more than 1.5 years among males within ten calendar years and they do not necessarily change mortality trends immediately after unification from one year to another. Research should rather focus on finding the factors that produce an immediate and continuous increase in average age at death causing these tempo distortions in life expectancy but do not necessarily increase the average length of life to the extent indicated by conventional life expectancy. Obviously, the same holds for the phase of rising differences prior to unification under changed conditions, with higher tempo distortions in life expectancy among the West German population. 
This paper presents a strong argument that the extent and the trend of the differences in mortality conditions between western and eastern Germany are not what we thought they were. It is not surprising, then, that none of the explanatory variables usually stated for the West-East German survival gap fit the observed mortality trends when measured by conventional life expectancy at birth. To come back to the central message made by Vaupel et al. (2003) on the closing East-West mortality gap in Germany: It may be never too late to increase the length of life, but changing survival conditions seems to take longer than trends in conventional life expectancy suggest, and the reasons for such changes may be of a different kind than generally expected.

Moreover, since life expectancy without adjustment for tempo effects is one of the demographic tools most used in order to analyze mortality, we may have to reconsider our knowledge on the basis of this measure:

- What about the opening and the recent closing of the mortality gap between women and men in the developed world?

- What about the linear increase in record life-expectancy at birth, described by Oeppen and Vaupel (2002), especially regarding the impressive slope of this increase?

- What about the increasing mortality gap between Eastern and Western Europe?

While tempo-adjustments of the TFR mainly lead to higher estimates on the hypothetical family size under current fertility conditions, this paper has shown that tempo-adjustment of life expectancy can provide a very different picture of current mortality conditions than does conventional life expectancy. We can expect that tempo effects distort the analysis in all cases where the compared populations experienced different trends in changing mortality. As the simple example used at the beginning of this paper has illustrated, we should not doubt the existence of tempo effects in period life expectancy and the distortions they possibly cause. It is, however, the method used, as proposed by Bongaarts and Feeney (2002) that may be in need of revision since it is based on a number of assumptions that will never be satisfied in full. While the constant shape assumption turned out to be robust against moderate deviations (Feeney, 2005), the no mortality under age 30 assumption seems problematic since the difference between $e_{0}$ and $e_{30}+30$ is interpreted as part of the measured tempo distortion (see Goldstein, 2005). ${ }^{6}$ Having accepted the existence of tempo effects, however, the method used to estimate tempo distortions should be preferred to using unadjusted estimates for period life expectancy as long as there are no better solutions. Thus, the main goal of formal demogra- 
phers' future work should be the development of methods for tempo-adjusted life expectancy based on less restrictive assumptions that can be applied to all contemporary and past populations, as claimed similarly by Feeney (2005) and Vaupel (2005).

\section{Acknowledgements}

For methodological advice and for running specific computer programs I am very grateful to Paola Di Giulio and Roland Rau, as well as to James Vaupel for fruitful discussions and helpful comments on an earlier version of this paper that was presented at the IUSSP XXV International Population Conference in Tours, France, July 18-23, 2005. Finally, I'd like to thank Susann Backer for her valuable language editing.

\section{References}

Becker N., Boyle P., 1997: "Decline in mortality from testicular cancer in West Germany after reunification", The Lancet 350: 744.

Bobak M., Marmot M., 1996a: "East-west mortality divide and its potential explanations: proposed research agenda", British Medical Journal 312: 421-425.

Bobak M., Marmot M., 1996b: "East-west health divide and potential explanations", in: Hertzman C., Kelly S., Bobak M. (Ed.): East-west life expectancy gap in Europe. Environmental and non-environmental determinants, Dordrecht et al.: Kluwer: 17-44.

Bongaarts J., Feeney G., 1998: “On the quantum and tempo of fertility”, Population and Development Review 24: 271-291.

Bongaarts J., Feeney G., 2002: “How long do we live?”, Population and Development Review 28: 13-29.

Bongaarts J., Feeney G., 2003: "Estimating mean lifetime”, Proceedings of the National Academy of Science 100: 13127-13133.

Bourgeois-Pichat J., 1985: "Recent changes in mortality in industrialized countries", in: Vallin J., Lopez A. D., Behm H. (Ed.): Health policy, social policy and mortality prospects, Liege: Ordina Editions: 507-539.

Brouard N., 1982: "Structure et dynamique des populations. La pyramide des années à vivre, aspects nationaux et examples régionaux", Espaces, Populations, Sociétés 2: 157-168. 
Bucher H., 2002: "Die Sterblichkeit in den Regionen der Bundesrepublik Deutschland und deren Ost-West-Lücke seit der Einigung“, in: Cromm J., Scholz R. D. (Ed.): Regionale Sterblichkeit in Deutschland, Augsburg and Göttingen: WiSoMed, Cromm: 33-38.

Caselli G., Egidi V., 1980: New trends in European mortality, Strasbourg: Council of Europe.

Chruscz D., 1992: “Zur Entwicklung der Sterblichkeit in geeinten Deutschland: die kurze Dauer des Ost-West-Gefälles“, Informationen zur Raumentwicklung 9-10: 691-700.

Dinkel R. H., 1992: “Kohortensterbetafeln für die Geburtsjahrgänge 1900 bis 1962 in den beiden Teilen Deutschlands“, Zeitschrift für Bevölkerungswissenschaft 18: 95-116.

Dinkel R. H., 1994: “Die Sterblichkeitsentwicklung der Geburtsjahrgänge in den beiden deutschen Staaten. Ergebnisse und mögliche Erklärungshypothesen“, in: Imhof A. E., Weinknecht R. (Ed.): Erfüllt leben - in Gelassenheit sterben: Geschichte und Gegenwart, Berlin: Duncker \& Humblot: 155-170.

Dinkel R. H., 1999: East and West German mortality before and after reunification, unpublished manuscript, University of Rostock.

Dorbritz J., Gärtner K., 1995: "Bericht 1995 über die demographische Lage in Deutschland”, Zeitschrift für Bevölkerungswissenschaft 20: 339-448.

Eberstadt N., 1994: "Demographic shocks after Communism: Eastern Germany, 1989-93”, Population and Development Review 20: 137-152.

Feeney G., 2003: Mortality tempo: a guide for the sceptic, unpublished manuscript, to be downloaded from http://www.gfeeney.com.

Feeney G., 2005: "Increments to life and mortality tempo", Demographic Research: forthcoming.

Gjonça A., Brockmann H., Maier H., 2000: “Old-age mortality in Germany prior to and after Reunification", Demographic Research 3: Article 1.

Goldstein J. R., 2005: "Found in translation? A cohort perspective on tempo-adjusted life expectancy", Demographic Research: forthcoming.

Guillot M., 2003a: "The cross-sectional average length of life (CAL): a cross-sectional mortality measure that reflects the experience of cohorts", Population Studies 57: 41-54.

Guillot M., 2003b: "Does period life expectancy overestimate current survival? An analysis of tempo effects in mortality", paper presented at the PAA 2003 Annual Meeting, Minneapolis, Minnesota, USA, May 1-3.

Guillot M., 2005: “Tempo effects in mortality: an appraisal”, Demographic Research: forthcoming. 
Hertzman C., Kelly S., Bobak M. (Ed.), 1996: East-west life expectancy gap in Europe. Environmental and non-environmental determinants, Dordrecht et al.: Kluwer.

Höhn C., Pollard J., 1991: "Mortality in the two Germanies in 1986 and trends 1976-1986", European Journal of Population 7: 1-28.

Horiuchi S., 2005: “Tempo effect on age-specific death rates”, Demographic Research 13: 189-200.

Kohler H.-P., Philipov D., 2001: „Variance effects in the Bongaarts-Feeney formula“, Demography 38: 1-16.

Lesthaeghe R., Willems P. 1999: "Is low fertility a temporary phenomenon in the European Union?", Population and Development Review 25: 211-228.

Luy M., 2004a: "Mortality differences between Western and Eastern Germany before and after Reunification: a macro and micro level analysis of developments and responsible factors", Genus 60: 99-141.

Luy M., 2004b: "Verschiedene Aspekte der Sterblichkeitsentwicklung in Deutschland von 1950 bis 2000", Zeitschrift für Bevölkerungswissenschaft 29: 3-62.

Luy M., 2005: "West-Ost-Unterschiede in der Sterblichkeit unter besonderer Berücksichtigung des Einflusses von Lebensstil und Lebensqualität”, in: Gärtner K., Grünheid E., Luy M. (Ed.): Lebensstile, Lebensphasen, Lebensqualität - Interdisziplinäre Analysen von Gesundheit und Sterblichkeit aus dem Lebenserwartungssurvey des BiB, Wiesbaden: VS-Verlag für Sozialwissenschaften: 333-364.

Mai R., 2004: "Regionale Sterblichkeitsunterschiede in Ostdeutschland. Struktur, Entwicklung und die Ost-West-Lücke seit der Wiedervereinigung”, in: Scholz R., Flöthmann J. (Ed.): Lebenserwartung und Mortalität, Materialien zur Bevölkerungswissenschaft 111, Wiesbaden: BiB: 51-68.

Meslé F., Hertrich V., 1997: "Mortality trends in Europe: the widening gap between east and west”, in: 23rd International Population Conference, Beijing 1997, Liège: IUSSP: 479508.

Meslé F., Vallin J., 2002: "Mortality in Europe: the divergence between east and west", Рориlation-E 57: 157-198.

Müller C. K. E., 1976: Die Säuglingssterblichkeit in der Bundesrepublik Deutschland und in der Deutschen Demokratischen Republik, Bonn: Schwarzbold.

Nolte E., Shkolnikov V., McKee M., 2000a: “Changing mortality patterns in east and west Germany and Poland: I. Long-term trends", Journal of Epidemiology and Community Health 54: 890-899. 
Nolte E., Shkolnikov V., McKee M., 2000b: “Changing mortality patterns in east and west Germany and Poland: II. Short-term trends during transition and in the 1990s”, Journal of Epidemiology and Community Health 54: 899-906.

Nolte E., Scholz R., Shkolnikov V., McKee M., 2002: “The contribution of medical care to changing life expectancy in Germany and Poland", Social Science \& Medicine 55: 1905-1921.

Oeppen J., Vaupel J. W., 2002: „Broken limits to life expectancy“, Science 296: 1029-1031.

Philipov D., Kohler H.-P., 2001: „Tempo effects in the fertility decline in Eastern Europe: evidence from Bulgaria, the Czech Republic, Hungary, Poland, and Russia“, European Journal of Population 17: 37-60.

Riphahn R. T., 1999: "Die Mortalitätskrise in Ostdeutschland und ihre Reflektion in der Todesursachenstatistik", Zeitschrift für Bevölkerungswissenschaft 24: 329-363.

Rodriguez G., 2005: „Demographic translation and tempo effects: an accelerated failure time perspective", Demographic Research: forthcoming.

Scholz R. D., 1996: “Analyse und Prognose der Mortalitätsentwicklung in den alten und neuen Bundesländern - Ergebnisse des Ost/West-Vergleiches der Kohortensterblichkeit”, in: Dinkel R. H., Höhn C., Scholz R. D. (Ed.): Sterblichkeitsentwicklung - unter besonderer Berücksichtigung des Kohortenansatzes, München: Boldt: 89-102.

Schott J., Wiesner G., Casper W., Bergmann K. E., 1994: “Entwicklung der Mortalität des alten Menschen in Ost- und Westdeutschland in den zurückliegenden Jahrzehnten”, in: Imhof A. E., Weinknecht R. (Ed.): Erfüllt leben - in Gelassenheit sterben: Geschichte und Gegenwart, Berlin: Duncker \& Humblot: 171-182.

Sobotka T., 2004: "Is lowest-low fertility in Europe explained by the postponement of childbearing?", Population and Development Review 30: 195-220.

Vallin J., Meslé F., 2001: “Trends in mortality in Europe since 1950: age-, sex- and causespecific mortality", in: Trends in mortality and differential mortality, Strasbourg, Council of Europe Publishing (Population Studies No. 36): 31-186.

Vaupel J. W., 2002: "Life expectancy at current rates vs. current conditions: a reflexion stimulated by Bongaarts and Feeney's 'How Long Do We Live?'”, Demographic Research 7: 365-377.

Vaupel J. W., 2005: “Lifesaving, lifetimes and lifetables”, Demographic Research: forthcoming.

Vaupel J. W., Carey J. R., Christensen K., 2003: “It's never too late”, Science 301: 16791681. 
Wachter K., 2005: “Tempo and its tribulations”, Demographic Research 13: 201-222.

Wilmoth J. R., 2005: “On the relationship between period and cohort mortality”, paper presented at the PAA 2005 Annual Meeting, Philadelphia, Pennsylvania, USA, March 31 April 2.

Zeng Yi, Land K. C., 2001: „A sensitivity analysis of the Bongaarts-Feeney method for adjusting bias in observed period total fertility rates“, Demography 38: 17-28.

Zeng Yi, Land K. C., 2002: “Adjusting period tempo changes with an extension of Ryder's basic translation equation", Demography 39: 269-285. 


\section{Appendix}

(a) Euler's method to solve a differential equation

The following description of the so-called Euler's method is taken from "Keshet's Typed Notes (2004)", Chapter 9.13, pp. 16-17. 'When it is difficult or impossible to find the solution desired for a differential equation by making guesses, by using integration methods, or from previous experience, it is possible to use approximation methods and numerical computations to do the job. Most of these methods rely on the fact that derivatives can be approximated by finite differences. For example, suppose a differential equation of the form

$$
\frac{d y}{d t}=f(y)
$$

with initial value $y(0)=y_{0}$, can be approximated by selecting a set of time points $t_{1}, t_{2}, \ldots$, which are spaced apart by time steps of size $\Delta t$, and replace the differential equation with the approximate finite difference equation

$$
\frac{y_{1}-y_{0}}{\Delta t}=f\left(y_{0}\right)
$$

It relies on the approximation

$$
\frac{d y}{d t} \approx \frac{\Delta y}{\Delta t}
$$

which is a relatively good approximation for small step size $\Delta t$. Then, rearranging the approximation it follows that

$$
y_{1}=y_{0}+f\left(y_{0}\right) \Delta t
$$

Knowing the quantities on the right allows us to compute value $y_{1}$, i.e. the value of the approximate "solution" at time point $t_{1}$. It is then possible to continue generating the value at the next time point in the same way by approximating the derivative again as a secant slope. This leads to 
$y_{2}=y_{1}+f\left(y_{1}\right) \Delta t$

The approximation thus generated, leading to $y_{1}, y_{2}, \ldots$, is called Euler's method. The fact that this procedure is only an approximate solution for a differential equation should not lower the value of the results presented in this paper since the general Bongaarts/Feeney-equation (2) is based on more severe assumptions that are never perfectly satisfied. Thus, the results presented here are expected anyway to provide solely an impression of the extent to which tempo distortions may lead in the wrong direction when analyzing mortality differences between West and East Germany using conventional life table techniques. An important goal of future work in formal demography must be the development of new ways for estimating tempoadjusted life expectancy based on less restrictive assumptions.

\section{(b) Derivation of Equation (3)}

In order to apply Euler's method to solve equation (2) for $e_{0}{ }^{*}(t), f(y) \Delta t$ in Equations (7) and (8) has to be substituted by $\left\{-1 / b \cdot\left[1-d e_{0}{ }^{*}(t) / d t\right]\right\}$. From Equations (1) and (2) and using annual estimates for the Gompertz parameter $b$ it follows that the tempo distortion $S(t)$ can be estimated by

$$
S(t)=-\frac{1}{b(t)} \cdot \ln \left[1-\frac{d e_{0}^{*}(t)}{d t}\right]
$$

Since $b(t)$ varies only slightly over time (see Table 1 and Appendix c and d), the annual estimates of $b(t)$ may be substituted by an average value for $b(t)=b$, as Bongaarts and Feeney (2002) proposed in their first paper on mortality tempo. However, since this would imply another additional assumption, I used the annual estimates $b(t)$. Equation (9) can be rearranged to

$$
\ln \left[1-\frac{d e_{0}^{*}(t)}{d t}\right]=-b(t) \cdot S(t)
$$

this leads to 
$1-\frac{d e_{0}^{*}(t)}{d t}=\exp [-b(t) \cdot S(t)]$

Since time is measured in units of annual steps and applying Euler's method (assuming that the change is linear), $d e_{0}{ }^{*}(t) / d t$ can be represented by $e_{0}{ }^{*}(t)-e_{0}{ }^{*}(t+1)$ and Equation (11) becomes

$1-\left[e_{0}^{*}(t)-e_{0}^{*}(t+1)\right]=\exp [-b(t) \cdot S(t)]$,

which yields

$e_{0}^{*}(t)-e_{0}^{*}(t+1)=1-\exp [-b(t) \cdot S(t)]$,

and thus

$e_{0}^{*}(t+1)=e_{0}^{*}(t)+\{1-\exp [-b(t) \cdot S(t)]\}$.

Using Equation (1) and substituting $e_{0}(t)$ by $e_{0}(t)^{S}$ directly leads to Equation (3). As described in the main text, for the first year $-1950-$ I used $S(1950)=2.00$ as initial condition leading to an estimate of $e_{0}^{*}$ (1951) using equation (3). The same procedure was then repeated for each subsequent calendar year in order to determine the complete series of estimates for $e_{0}{ }^{*}(t)$ until the year 2000 . 
(c) Estimates of $e_{0}(t), e_{0}(t)^{S}, b, e_{0}{ }^{*}(t)$, and $S(t)$ for single calendar years, males, West and East Germany, 1975-2000 (no mortality under age 30)

\begin{tabular}{|c|c|c|c|c|c|c|c|c|c|c|}
\hline \multirow{2}{*}{$\frac{\text { Year }}{t}$} & \multicolumn{5}{|c|}{ West Germany } & \multicolumn{5}{|c|}{ East Germany } \\
\hline & $e_{0}(t)$ & $e_{0}(t)^{S}$ & $b$ & $e_{0}^{*}(t)$ & $S(t)$ & $e_{0}(t)$ & $e_{0}(t)^{S}$ & $b$ & $e_{0}^{*}(t)$ & $S(t)$ \\
\hline 1975 & 71.17 & 71.41 & 0.091 & 70.90 & 0.27 & 71.28 & 71.41 & 0.098 & 71.35 & -0.08 \\
\hline 1976 & 71.49 & 71.54 & 0.089 & 70.95 & 0.54 & 71.46 & 71.41 & 0.093 & 71.36 & 0.10 \\
\hline 1977 & 71.96 & 71.70 & 0.090 & 71.00 & 0.96 & 71.59 & 71.40 & 0.094 & 71.36 & 0.23 \\
\hline 1978 & 71.85 & 71.87 & 0.091 & 71.06 & 0.79 & 71.33 & 71.39 & 0.094 & 71.37 & -0.04 \\
\hline 1979 & 72.20 & 72.05 & 0.088 & 71.13 & 1.07 & 71.20 & 71.38 & 0.095 & 71.37 & -0.17 \\
\hline 1980 & 72.29 & 72.25 & 0.088 & 71.21 & 1.08 & 71.07 & 71.38 & 0.097 & 71.37 & -0.30 \\
\hline 1981 & 72.39 & 72.46 & 0.089 & 71.30 & 1.09 & 71.38 & 71.38 & 0.092 & 71.37 & 0.01 \\
\hline 1982 & 72.63 & 72.67 & 0.090 & 71.40 & 1.24 & 71.44 & 71.38 & 0.092 & 71.37 & 0.07 \\
\hline 1983 & 72.78 & 72.89 & 0.089 & 71.50 & 1.27 & 71.66 & 71.38 & 0.093 & 71.37 & 0.29 \\
\hline 1984 & 73.18 & 73.11 & 0.091 & 71.62 & 1.56 & 71.70 & 71.39 & 0.094 & 71.37 & 0.33 \\
\hline 1985 & 73.26 & 73.32 & 0.092 & 71.75 & 1.51 & 71.57 & 71.41 & 0.096 & 71.37 & 0.19 \\
\hline 1986 & 73.54 & 73.54 & 0.091 & 71.88 & 1.66 & 71.51 & 71.44 & 0.095 & 71.38 & 0.13 \\
\hline 1987 & 73.84 & 73.74 & 0.094 & 72.02 & 1.81 & 71.70 & 71.48 & 0.094 & 71.38 & 0.32 \\
\hline 1988 & 74.07 & 73.93 & 0.093 & 72.17 & 1.90 & 71.56 & 71.53 & 0.092 & 71.39 & 0.17 \\
\hline 1989 & 74.13 & 74.12 & 0.094 & 72.32 & 1.81 & 71.88 & 71.61 & 0.093 & 71.40 & 0.47 \\
\hline 1990 & 74.22 & 74.29 & 0.094 & 72.48 & 1.74 & 71.14 & 71.70 & 0.090 & 71.42 & -0.28 \\
\hline 1991 & 74.35 & 74.46 & 0.092 & 72.63 & 1.71 & 71.31 & 71.83 & 0.087 & 71.45 & -0.14 \\
\hline 1992 & 74.68 & 74.62 & 0.091 & 72.79 & 1.89 & 71.77 & 71.99 & 0.090 & 71.48 & 0.29 \\
\hline 1993 & 74.70 & 74.78 & 0.094 & 72.94 & 1.76 & 72.01 & 72.19 & 0.092 & 71.52 & 0.49 \\
\hline 1994 & 74.96 & 74.95 & 0.094 & 73.10 & 1.86 & 72.40 & 72.44 & 0.090 & 71.58 & 0.82 \\
\hline 1995 & 75.05 & 75.13 & 0.092 & 73.26 & 1.79 & 72.81 & 72.74 & 0.094 & 71.66 & 1.16 \\
\hline 1996 & 75.27 & 75.33 & 0.093 & 73.42 & 1.85 & 73.27 & 73.11 & 0.092 & 71.75 & 1.52 \\
\hline 1997 & 75.68 & 75.56 & 0.094 & 73.58 & 2.10 & 73.89 & 73.55 & 0.095 & 71.87 & 2.02 \\
\hline 1998 & 75.99 & 75.85 & 0.094 & 73.75 & 2.24 & 74.43 & 74.09 & 0.095 & 72.02 & 2.41 \\
\hline 1999 & 76.28 & 76.22 & 0.095 & 73.93 & 2.34 & 74.82 & 74.72 & 0.099 & 72.20 & 2.62 \\
\hline 2000 & 76.54 & 76.67 & 0.093 & 74.13 & 2.42 & 75.03 & 75.46 & 0.096 & 72.42 & 2.61 \\
\hline
\end{tabular}


(d) Estimates of $e_{0}(t), e_{0}(t)^{S}, b, e_{0}{ }^{*}(t)$, and $S(t)$ for single calendar years, females, West and East Germany, 1975-2000 (no mortality under age 30)

\begin{tabular}{|c|c|c|c|c|c|c|c|c|c|c|}
\hline \multirow{2}{*}{$\frac{\text { Year }}{t}$} & \multicolumn{5}{|c|}{ West Germany } & \multicolumn{5}{|c|}{ East Germany } \\
\hline & $e_{0}(t)$ & $e_{0}(t)^{S}$ & $b$ & $e_{0}^{*}(t)$ & $S(t)$ & $e_{0}(t)$ & $e_{0}(t)^{S}$ & $b$ & $e_{0}^{*}(t)$ & $S(t)$ \\
\hline 1975 & 76.84 & 77.04 & 0.101 & 75.59 & 1.25 & 75.91 & 76.05 & 0.106 & 75.34 & 0.57 \\
\hline 1976 & 77.17 & 77.23 & 0.100 & 75.73 & 1.44 & 76.15 & 76.09 & 0.105 & 75.41 & 0.74 \\
\hline 1977 & 77.74 & 77.44 & 0.102 & 75.87 & 1.87 & 76.53 & 76.13 & 0.103 & 75.48 & 1.06 \\
\hline 1978 & 77.74 & 77.66 & 0.101 & 76.01 & 1.73 & 76.34 & 76.18 & 0.106 & 75.54 & 0.79 \\
\hline 1979 & 78.03 & 77.89 & 0.099 & 76.17 & 1.86 & 76.40 & 76.24 & 0.106 & 75.61 & 0.80 \\
\hline 1980 & 78.27 & 78.13 & 0.102 & 76.32 & 1.95 & 76.17 & 76.30 & 0.105 & 75.67 & 0.50 \\
\hline 1981 & 78.34 & 78.37 & 0.102 & 76.49 & 1.85 & 76.37 & 76.37 & 0.105 & 75.74 & 0.63 \\
\hline 1982 & 78.57 & 78.62 & 0.102 & 76.67 & 1.90 & 76.57 & 76.46 & 0.105 & 75.80 & 0.77 \\
\hline 1983 & 78.76 & 78.86 & 0.102 & 76.85 & 1.91 & 76.82 & 76.56 & 0.106 & 75.87 & 0.95 \\
\hline 1984 & 79.23 & 79.10 & 0.102 & 77.03 & 2.20 & 76.85 & 76.67 & 0.107 & 75.94 & 0.91 \\
\hline 1985 & 79.30 & 79.32 & 0.104 & 77.22 & 2.08 & 76.77 & 76.80 & 0.107 & 76.01 & 0.76 \\
\hline 1986 & 79.47 & 79.54 & 0.106 & 77.42 & 2.05 & 76.73 & 76.95 & 0.112 & 76.09 & 0.63 \\
\hline 1987 & 79.82 & 79.74 & 0.108 & 77.62 & 2.20 & 77.14 & 77.13 & 0.111 & 76.19 & 0.96 \\
\hline 1988 & 80.02 & 79.93 & 0.105 & 77.83 & 2.20 & 77.17 & 77.32 & 0.108 & 76.28 & 0.88 \\
\hline 1989 & 80.07 & 80.10 & 0.104 & 78.02 & 2.05 & 77.49 & 77.54 & 0.105 & 76.39 & 1.10 \\
\hline 1990 & 80.05 & 80.25 & 0.105 & 78.22 & 1.84 & 77.44 & 77.79 & 0.103 & 76.50 & 0.94 \\
\hline 1991 & 80.26 & 80.39 & 0.106 & 78.41 & 1.85 & 77.69 & 78.06 & 0.101 & 76.63 & 1.06 \\
\hline 1992 & 80.59 & 80.52 & 0.104 & 78.60 & 1.99 & 78.38 & 78.36 & 0.108 & 76.76 & 1.62 \\
\hline 1993 & 80.50 & 80.63 & 0.106 & 78.78 & 1.72 & 78.86 & 78.68 & 0.106 & 76.92 & 1.94 \\
\hline 1994 & 80.78 & 80.75 & 0.107 & 78.96 & 1.82 & 79.18 & 79.03 & 0.118 & 77.09 & 2.08 \\
\hline 1995 & 80.89 & 80.87 & 0.107 & 79.13 & 1.76 & 79.53 & 79.41 & 0.108 & 77.30 & 2.24 \\
\hline 1996 & 80.98 & 81.01 & 0.106 & 79.30 & 1.68 & 79.86 & 79.82 & 0.105 & 77.50 & 2.36 \\
\hline 1997 & 81.32 & 81.18 & 0.108 & 79.47 & 1.86 & 80.43 & 80.25 & 0.115 & 77.72 & 2.71 \\
\hline 1998 & 81.55 & 81.40 & 0.108 & 79.64 & 1.91 & 80.76 & 80.70 & 0.111 & 77.97 & 2.79 \\
\hline 1999 & 81.71 & 81.69 & 0.108 & 79.81 & 1.90 & 81.18 & 81.17 & 0.115 & 78.23 & 2.95 \\
\hline 2000 & 81.93 & 82.08 & 0.108 & 79.99 & 1.93 & 81.47 & 81.66 & 0.113 & 78.52 & 2.95 \\
\hline
\end{tabular}




\section{Endnotes}

${ }^{1}$ Goldstein (2005) showed that in conditions of steady mortality change tempo-adjusted life expectancy with the Bongaarts and Feeney formula can indeed be used as a measure of cohort life expectancy. However, since the formula contains no direct cohort component - as will be shown in a subsequent section of this paper - the primary interpretation should be done in a period context.

${ }^{2}$ In the paper mentioned, Vaupel (2002) regarded the distortions inherent in the current mortality rates as a consequence of the changed timing of death resulting from the effects of heterogeneity rather than from the effects of mortality tempo. Regardless of the different views on the origin of distortions in period mortality rates, Vaupel's message applies universally to all kinds of demographic period measures.

${ }^{3}$ In West Germany, the result of childbirth is defined as live birth if one of three signs of life, namely heart-beat, natural respiration, or a pulsating umbilical cord, is evident. In East German statistics, live birth was defined only by the simultaneous existence of heartbeat and natural respiration (Müller, 1976). Consequently, all deaths of new-borns showing only one of the three signs of life are registered as live births, and thus as infant deaths only in West Germany, whereas in East Germany such cases were registered as stillbirths, and did not enter infant mortality statistics.

${ }^{4}$ The application of a Gompertz model requires the assumption that mortality under age 30 is negligible since the Gompertz model does not fit the pattern of mortality in ages below 30. As this assumption is close to reality in modern populations with high life expectancy it can be accepted as being applicable to West and East Germany from 1975 to 2000. However, this method cannot be used in populations with high mortality in infancy, childhood, and young adult ages.

${ }^{5}$ Bongaarts and Feeney (2002) fitted the age-specific death rates until age 100. For West and East Germany, however, official population and death data are available only until age 90.

${ }^{6}$ Note that in Bongaarts and Feeney's (2002) tempo-adjustment formula the same holds for the difference between $e_{0}(t)$ and $e_{0}(t)^{S}$. However, this difference can lead to a counterfactual increase as well as to a counterfactual decrease of the estimated tempo effect.

7 Keshet's textbook "Math 102 Course Notes (2004)“ is available online and can be downloaded from http://ugrad.math.ubc.ca/coursedoc/math102/keshet.notes/index.html 